\title{
Could GARCH-VaR method measure mutual fund risk in post-crisis era China effectively?
}

\author{
Benzhao Zhang ${ }^{1}$ Chi Zhang ${ }^{2}$ \\ ${ }^{1}$ School of Economics, Hefei University of Technology, Hefei, Anhui, China,230601, \\ ahzbz@126.com \\ ${ }^{2}$ School of Economics, Hefei University of Technology, Hefei, Anhui, China,230601, \\ anhuizhc@hotmail.com
}

\begin{abstract}
In order to evaluate mutual fund risk in post-crisis era China, this paper constructs two VaR-GARCH models, and estimates the VaR of different mutual funds under t-distribution and generalized error distribution(GED) separately. Then by employing Kupiec back-testing method, we test the accuracy of two VaRGARCH models. It turns out that the VaR model under GED is better than the other one in reflecting mutual fund risk but neither holds the marked back-testing effect.
\end{abstract}

Keywords: mutual fund; VaR method; GARCH model; t-distribution; GED

\section{Introduction}

Post-crisis era refers to the period when financial crisis is past. During this period, the crisis root causing worldwide financial turbulence attenuates but has not completely disappeared. Economy turns stable with many uncertainty instead of turbulence. In the second half of 2008, the subprime crisis originating from America has swept over the world, and greatly shocked the major economy entities like US, EU, China and Japan. In response to the crisis, world governments have initiated a series economic stimulus package. On December $31^{\text {th }}$ of 2008 , US Congress passed the $\$ 700$ billion Recov- ery and Reinvestment Act. On November $10^{\text {th }}$ of 2008 , China government unveiled incentive plans which would cost tax payers $¥ 4$ trillion (amounting to $\$ 588$ billion in 2008). Since the second quarter of 2009, with the effort of world nations, global economic sentiment was on a gradual recovery, Economic Leading Indicator and PMI rebounded, and global economy entered post-crisis era.

The first official mutual fund-the Massachusetts Investors Trust-was established in 1924, and China's first mutual fund did not appear until September in 2001. Ever since the establishment of mutual funds, their numbers and scales have been on a rise. As one of investment vehicles, mutual fund has higher fluidity and flexibility compared with closed-end fund and is preferred by investors. However, in company with its rapidly increase, mutual fund has also displayed its risk in recent years.

According to Wind Database, facilitated by no less than 8 percent GDP growth rate in China, mutual fund market has grown fast in quantity as well as in net worth before 2008. On the one hand, mutual fund quantity has kept its pace before and after crisis. On the other hand, mutual fund net value reached its peak in 2007. Net value has quadrupled from $¥ 700$ billion to ¥3 trillion from 2006 to 2007 . However, subprime crisis in 2008 im- 
pacted financial market in China, including mutual fund market, so net value was declined by $43 \%$. This is the first drop for the developing market within a decade. Ever since then, mutual fund market in China began to fluctuate. Until the end of 2012, though the quantity is over one thousand, the net worth has never reached its peak again. For its influence on economy and finance stability, it is significant to initiate risk research under current condition. This paper will employ VaR method to analyze data from mutual fund market.

\section{Model and Method}

\subsection{VaR Method based on GARCH Model}

In recent years, domestic and foreign scholars have obtained coincident conclusion on the validity of VaR method when measuring mutual fund risk. They believe that VaR-GARCH model with GED measure mutual fund risk effectively, but they focus mainly on the market before crisis occurs but fail to consider it after crisis. Hence this paper will discuss whether VaR-GARCH still works in postcrisis mutual fund market in China.

Quantities of paper reveal that volatility of financial time series does not display normal distribution, but has the feature of leptokurtosis and heavy tails as time passes by. Traditional econometric models cannot depict such time sequence. The first model which could do this job was Autoregressive Conditional Heteroskedasticity model (ARCH), formulated by Engle in 1982. The model is simple, but many variables are needed to indicate progress of return on assets. Then, in 1986 Bollerslev presented a better version called Generalized Autoregressive Conditional Heteroskedasticity model (GARCH).

For logarithmic rate of return $r_{t}$, we name

$$
r_{t}=c_{0}+\sum_{i=1}^{k} \phi_{i} r_{t-i}^{2}+\sum_{j=1}^{m} \phi_{j} a_{t-j}^{2}-a_{t}
$$

and when $\mathrm{a}_{\mathrm{t}}$ meets following equations, we deem $a_{t}$ comply with $\operatorname{GARCH}(m, s)$ model.

$$
\begin{gathered}
a_{t}=\varepsilon_{t} \sigma_{t} \\
\sigma_{t}^{2}=\alpha_{0}+\sum_{i=1}^{m} \alpha_{i} a_{t-i}^{2}+\sum_{j=1}^{s} \beta_{j} \sigma_{t-j}^{2} \text { (2) }
\end{gathered}
$$$$
\text { 到引用源。 }
$$

where $\left\{\varepsilon_{t}\right\}$ represents independent and identically distributed random variables with mean 0 and variance 1 , $\alpha_{0}>0, \alpha_{i} \geq 0, \beta_{j} \geq 0, \sum_{i=1}^{\max (\mathrm{m}, \mathrm{s})} \alpha_{i}+\beta_{i}<1$. The limit on $\alpha_{i}+\beta_{i}<1$ can guarantee that unconditional variance of $\alpha_{t}$ is limited, and conditional variance $\sigma_{t}^{2}$ is timedependent.

Conditional variance $\sigma_{t}$ is symmetric function of $\varepsilon_{t-i}$ 错误!未找到引用源。. It is absolute value of $\varepsilon_{t-i}$ that affect $\sigma_{t}$ instead of the sign. But in reality, financial price movements have a leverage effect, namely, rise and fall of stock price may have asymmetrical effect on subsequent fluctuations. The fall has a great power than the rise. In order to cover the shortage, Nelson proposed exponential GARCH model (EGARCH) with a new $\sigma_{t}^{2}$ equation while others remain fixed.

$$
\begin{gathered}
\ln \sigma_{t}^{2}=\alpha_{0}+\sum_{i=1}^{s}\left(\alpha_{i}\left|\frac{a_{t-i}}{\sigma_{t-i}}\right|+\alpha_{i} \gamma_{i} \frac{a_{t-i}}{\sigma_{t-i}}\right)+ \\
\sum_{j=1}^{m} \beta_{j} \ln \sigma_{t-j}^{2}
\end{gathered}
$$

where positive and negative $a_{t-i}$ make different contributions for $\ln \sigma_{t}^{2}$ 错误!未找 到引用源。, and ensure asymmetry of EGARCH.

Under normal circumstances, we assume that $\varepsilon_{t}$ complies with $\mathrm{t}$ distribution or GED. When freedom degree of $t$ distribution approaches infinity, the probability density function of $t$ distribution is equal to that of normal distribution. And when it approached zero, it has leptokur- 
tosis and heavy tails. As for GED, it will have heavier tails and sharper summit than normal distribution when its freedom degree is less than two.

We can use the following formula to estimate VaR of mutual fund after obtaining conditional variance: $\operatorname{VaR}=Z_{\alpha} \sigma \sqrt{\Delta}$ 错 误!未找到引用源。(where $\Delta t$ represents expiry date, $\sigma$ means standard deviation of predicted return, $Z_{\alpha}$ is quantile of specific confidence coefficient under correspondent distribution). In this paper, we select one dealing day so the formula becomes $\operatorname{VaR}=Z_{\alpha} \sigma$.

\subsection{VaR Model Back Testing}

VaR model back testing refers to coverage degree of measurement result of VaR model on actual loss. This paper adopts failure frequency test method proposed by Kupiec in 1995. It assumes that VaR has time independence, and if actual loss is more than VaR, we deem it as failure, if actual loss is smaller than VaR, we deem it as success.

\section{Empirical Analysis}

\subsection{Sample Selection and Time Set}

We select 15 funds founded between 2002 and 2006 as research sample, which have been well developed with a longer history. Five of them are stock mutual funds: Yifangdace Strategy Progress (YSP), Huaan Innovation (HI), Milky Way Steady (MYS), Taida Bonus (TB), Rongtong Tongli(RT); five are bond mutual funds: South Hedge Accretion (NHA), Xingye Convertible Debt (XCD), South Baoyuan(SB), Jiashi Bond(JB), Nuoan Opimize Revenue(NOR); and the other five are mixed mutual funds: Baoying Hongli(BH), Great Wall Jiucheng(CWJ), Guotai Jinying(GJ), Huaxia Rtibution(HR), Dacheng Valuation(DV).

This paper employs daily return rate from January $5^{\text {th }}, 2009$ to March $30^{\text {th }}$, 2012 for parameter estimation and VaR calculation, and those data from April $3^{\text {rd }}$, 2012 to March $30^{\text {th }}, 2013$ for back testing on VaR model. In the paper, $r_{t}=\ln p_{t}-\ln p_{t-1}$, where $r_{t}$ represents fund growth rate of net value, 错误!未找 到引用源。 $p_{t}$ is net value of $t$ day.

\subsection{Preliminary Date Analysis}

Statistics: among 15 funds, 3 of them have negative YIELD mean and the left are positive. Their standard deviation are all high, indicating YIELD varying remarkably. Under 5\% significance level, 14 funds revenue sequences are obvious left-skewed shows that most fund YIELD distributions have left trails. The minimum kurtosis is 3.96035 which means the sequences have leptokurtosis and heavy tails. The minimum Jarque-Bera Test result is 41.04085 and the whole are significant under 5\% significance level which shows the sequences display abnormal distribution

Stationary Test: ADF Test results show that the daily return rate sequences will turn down null hypothesis under $1 \%$ significance level. The sequence does not have unit root and is stationary.

Autocorrelation Test: test results show each sequence autocorrelation is not significant under 5\% significance level which means there is no autocorrelation between daily return rates.

ARCH Test: ARCH-LM Test results indicate that all accompany probability $\mathrm{p}$ value of $O b s * R^{2}$ 错误!未找到引用源。 are less than $5 \%$, namely, all sequences have heteroscedasticity.

\subsection{Empirical Result and Analysis}

We employ GARCH(1,1) normal distribution model, GARCH(1,1) t distribution model, GARCH(1,1) GED model, $\operatorname{EGARCH}(1,1) \mathrm{t}$ distribution model, and EGARCH(1,1) GED model respectively and get parameter value and freedom de- 
gree of $t$ distribution and GED.

Firstly, according to statistics, in GARCH-t and GARCH-GED models, all $\alpha$ and $\beta$ values are significant under $5 \%$ significance level, illustrating that past fluctuations have obvious influence on current fluctuations, which verifies volatility cluster of each daily return rate sequence. Secondly, $\alpha<0.25, \beta>0.75$ applies to every sequence. This means daily return fluctuation has a certain degree of continuity and quick reaction to variation of market. Thirdly, $\alpha+\beta<1$ applies to 12 funds except SHA, JB and BH. It explains that conditional variances have strong memorability, fluctuations lasts long and overall risk of fund is high. Fourthly, freedom degree of $\mathrm{t}$ distribution in every model is less than 9 , while that of GED is less than 2. Every sequence has a heavy tail. Last, AIC of every model is low(less than -5.7), reflecting precision and briefness of model, and demonstrates that model fitting is preferable.

\subsection{VaR Calculation}

Since China mutual funds have heavy tails and inconspicuous leverage effect, this paper selects GARCH-t and GARCH-GED models to calculate VaR. We calculate VaR in different situations and results are shown in Table 1.

Table 1: VaR of each model in different significance level

\begin{tabular}{lllll}
\hline Name & \multicolumn{2}{l}{$95 \%$ significance level } & \multicolumn{2}{l}{$99 \%$ significance level } \\
\cline { 2 - 5 } & GARCH-t & GARCH-GED & GARCH-t & GARCH-GED \\
YSP & 0.067085 & 0.059606 & 0.104490 & 0.091786 \\
HI & 0.012283 & 0.010588 & 0.019492 & 0.016669 \\
MYS & 0.012989 & 0.011628 & 0.020106 & 0.017788 \\
TB & 0.018588 & 0.016678 & 0.028865 & 0.025461 \\
RT & 0.022486 & 0.018480 & 0.037322 & 0.029871 \\
NHA & 0.018791 & 0.015206 & 0.031206 & 0.024802 \\
XCD & 0.015262 & 0.011314 & 0.026904 & 0.019409 \\
SB & 0.008980 & 0.007746 & 0.014304 & 0.012168 \\
JB & 0.006844 & 0.005173 & 0.011972 & 0.007869 \\
NOR & 0.006271 & 0.003829 & 0.012045 & 0.006745 \\
BH & 0.014354 & 0.010348 & 0.025444 & 0.016305 \\
CWJ & 0.020830 & 0.018657 & 0.032100 & 0.027660 \\
GT & 0.015337 & 0.013332 & 0.024310 & 0.020499 \\
HR & 0.017291 & 0.015407 & 0.026804 & 0.023584 \\
DV & 0.012788 & 0.011165 & 0.020147 & 0.017551 \\
\hline
\end{tabular}

In the light of Table 1 , VaR of GARCH(1,1) GED model is higher than that of $\operatorname{GARCH}(1,1) \mathrm{t}$ distribution model when significance lever is $95 \%$ or $99 \%$. It explains that $\operatorname{GARCH}(1,1) \mathrm{t}$ distribution model may overestimate risk. By comparing VaR between different kinds of mutual funds, we find that bond mutual funds have the minimum $\mathrm{VaR}$, indicating a lower risk than that of the left two.

\subsection{VaR Back Testing Analysis}

To evaluate validity of the risk measuring model we have constructed, we need calculate VaR's coverage on actual loss. This paper employs Kupiec's failure frequency method to test it. The sample $\mathrm{T}$ we use for test are daily return rate from April $3^{\text {rd }}$, 2012 to March $30^{\text {th }} 2013$, totaling 242 days, then we figure out exception days $\mathrm{N}$,

$$
N=\sum_{t=1}^{T} N_{t}, N_{t}=\left\{\begin{array}{l}
0, V a R \leq r_{t} \\
1, V a R>r_{t}
\end{array}\right.
$$

In accordance with this method, when significance level is $95 \%$, we cannot turn down null hypothesis if $N \in[5,18]$ 错误! 
未找到引用源。 and model undergoes testing. $N>18$ means model underestimate loss probability while $N<5$ 错误!未 找到引用源。indicates a conservative model. For $99 \%$ significance level, model undergoes testing when $N \in[1,6]$. All results are in Table 2 .

Table 2: Exception days of each model in different significance level

\begin{tabular}{|c|c|c|c|c|}
\hline \multirow[t]{2}{*}{ Name } & \multicolumn{2}{|c|}{$95 \%$ significance level } & \multicolumn{2}{|c|}{ 99\% significance level } \\
\hline & $\begin{array}{l}\text { GARCH-t Ex- } \\
\text { ception Days }\end{array}$ & $\begin{array}{l}\text { GARCH-GED } \\
\text { Exception Days }\end{array}$ & $\begin{array}{l}\text { GARCH-t Ex- } \\
\text { ception Days }\end{array}$ & $\begin{array}{l}\text { GARCH-GED } \\
\text { Exception Days }\end{array}$ \\
\hline YSP & 0 & 0 & 0 & 0 \\
\hline HI & 19 & 30 & 2 & 8 \\
\hline MYS & 18 & 23 & 2 & 3 \\
\hline $\mathrm{TB}$ & 16 & 22 & 2 & 3 \\
\hline RT & 3 & 8 & 0 & 1 \\
\hline NHA & 0 & 0 & 0 & 0 \\
\hline $\mathrm{XCD}$ & 2 & 5 & 0 & 1 \\
\hline SB & 4 & 12 & 0 & 0 \\
\hline JB & 1 & 1 & 0 & 1 \\
\hline NOR & 0 & 1 & 0 & 0 \\
\hline BH & 9 & 26 & 0 & 8 \\
\hline CWJ & 3 & 5 & 0 & 0 \\
\hline GT & 21 & 30 & 7 & 9 \\
\hline HR & 5 & 7 & 0 & 0 \\
\hline DV & 24 & 29 & 12 & 16 \\
\hline
\end{tabular}

From Table 2, when significance level is $95 \%$, GARCH-t model has four funds undergoing test while GARCH-GED has five. When significance level is $99 \%$, GARCH-t model has three funds undergoing test while GARCH-GED has five. VaR of GARCH-t model is obviously overestimated in that exception days of ten funs is null while GARCH-GED model only has six funds that have null exception days. Relatively speaking, GARCH-GED model is slightly superior to GARCH-t model.

\section{Conclusions and Research Prospect}

\subsection{Conclusions}

This paper analyzes and compares mutual funds' VaR in post-crisis era China with GARCH(1,1)-t and GARCH-GED model. The results revealed that the daily return rate sequences of 15 funds display abnormal distributions, have volatility clus- ter and heavy tails. $\mathrm{T}$ distributions can depict leptokurtosis and heavy tails but VaR of GARCH-t model will overestimate real risk relatively.

Though GARCH-GED can measure real risk relatively, Table 2 indicates that back testing results of neither model is obvious. When significance level is $95 \%$, GARCH-t model overestimates risk while GARCH-GED underestimates the risk. When significance level is $99 \%$, both models overestimate risk. We verify the statement that GARCH-GED model is better than GARCH-t model but fail to reach a conclusion that GARCH-GED model has an obvious back testing effect. Several reasons may account for this.

Firstly, Kupiec method needs further improvement. For low exception rate, it has difficulty in finding system deviation because of its small probability; and for high exception rate, it cannot satisfactorily distinguish different distribution of residual. 
Secondly, previous researches mainly concentrate on period before crisis, but market performance after crisis is entirely different from before. VaR method based on GARCH model measures risk before crisis effectively, but this cannot guarantee applicability for market after crisis. And this paper confirms this conclusion.

Thirdly, China has giant quantity of funds, 1105 funds are registered before December 31st, 2012. For space limit of this paper, we select only 15 of them all founded before 2006, but do not consider those set up in recent years. From 2008 to 2012 , though plenty of funds were established every year, (98 in 2008, 116 in 2009, 153 in 2010, 207 in 2011, 160 in 2012), and they constitute a significant part of market, yet their data is not enough to engage large sample statistics.

\subsection{Research Prospect}

In order to measure mutual fund risk precisely, we could do further exploration on following aspects. For instance, among mutual funds built in post-crisis era, their daily return rate sequences do not meet the prerequisites of $\operatorname{GARCH}(1,1)$ model. Therefore, in reality, we can consider GARCH model with different parameters and EARCH, LARCH and other models. Besides, for these funds with a short history of development, Kupiec method faces deficiency of data in current mutual fund market. As a consequence, researches on emerging funds and updated VaR back testing method will be our next target.

\section{References}

[1] Phlippe Bouchaud, Marc Potters, "Noise Dressing of Financial Correlation Matric," Physical Review Letters, pp.1467-1470, 1999.
[2] Goorbergh, Vlaar P, "Value-at-Risk: Analysis of Stock Returns Historical Simulation," Journal of Business, pp.21-33, 1999 (5).

[3] Christoffersen Errunza, Vihang, "Towards a Global Financial Architecture: Capital Mobility and Risk Management Issues," Emerging Markets Review, pp.3-20, 2000(5).

[4] John Graham, Campbell Harvey, "Expectations of Equity Risk Premia, Volatility and Asymmetry from a Corporate Finance Perspective," NBER Working Paper, 2001.

[5] Angel Idis, "The use of GARCH models in VaR estimation," Statistical Methodology, pp.17-18, 2004(2).

[6] Zhenquan Zhao, Xiaozhou Li, "Empirical Research of Risk of Different Kinds of Mutual Funds," Contemporary Economics Research, pp. 51-55, 2006(4).

[7] Zejiong Zhou, Benshan Shi, "The Day-of-the-Week Effect on Returns of Mutual Fund and Its Volatility in China," Finance and Trade Research, pp.59-64, 2005(6).

[8] Quanbao Chen, Juan Lian, “Analysis of the Risk of Mutual Fund Using VaR Method-Based on GARCH Model in China," On Economic Problems, pp.36-40, 2008(9).

[9] Linfen Chen, Dequan Wang, "Research of Risk on Stock Market Using VaR Method Based on GARCH Model," Journal of Industrial Technological Economics, pp.47-51, 2009(11).

[10] Ziping Du, Hui He, Yong Zhang, Jiayi Feng, "Study on VaR of Mutual Fund based on GJR-Alaplace Model," Technoeconomics and Management Research,pp.8689,2011. 
